\title{
Concerning the Myrsinaceae ("Ardisiaceae") of Japan II
}

\author{
By Egbert H. WALKER*
}

WALKER, E.H：日本のヤブコウジ科（ヤマタチバナ科）について II

Received May 1, 1954

\section{SOME CRITICAL GENERA AND SUBGENERIC TAXA}

\section{Maesa.}

\section{Subdivisions :}

Nakai (18, pp. 6 and 11) divides Maesa into section Doraena and section Dartus. Whether or not this separation into two sections is justified is a matter of opinion. The species of Maesa can fairly readily be separated into two groups on the relative length of the corolla tube and corolla lobes. Comparison of Nakai's Latin descriptions of these sections reveals no other significant differences. Neither Mez nor I nor any other workers have considered any valuable objective gained by formalizing this distinction, and using discarded generic names, such as Doraena Thunb. and Dartus Lour., to designate them as sections. One wonders whether this distinction of length of corolla tube would remain as definite as it seems to be for the eastern Asiatic species, if all species of the genus Maes $a$ were considered.

\section{Species and subspecific taxa :}

(a) Maesa japonica f. gracilis (Benth.) Nakai (Nakai, p. 9): This variant was first published as $M$. coriacea var. gracilis Benth. Fl. Hongkong. 204. 1861 with the following description:

"Leaver narrower, almost lanceolate, racemes and pedicels more slender

and longer, and corolla rather smaller. Hongkong, Wilford; and some of

Champion's early specimens in young bud appear to be referable to this form." It was overlooked by $\mathrm{Mez}$ (12) and by me (29), but was taken up by Nakai as Maesa japonica f. gracilis (Benth.) Nakai.

I have examined, on loan from the Kew Herbarium, a Wilford specimen from Hongkong, originally in the Bentham Herbarium. It was labeled first as "Maesa coriacea Champ. var. gracilis" in Bentham's handwriting, later designated as “ $M$. Doraena, Blume-Index Florae Sinenses." This specimen was selected by E. D. Merrill while he was working at Kew in 1951 as evidently the type of this variety. It was

\footnotetext{
* Associate Curator, Department of Botany, United States National Museum, Smithsonian Institution Washington, D.C.
} 
filed with $M$. japonica, but did not appear to belong in that alliance, so it was sent on loan to me, after the preliminary sending of a fragment and a rubbing from the leaves left room for doubt of its true status.

It is reasonably certain that this is Bentham's type. It does indeed show some characters of Maesa japonica, which is the earliest name for $M$. coriacea Champ. and $M$. doraena Blume, but differences show it is not the same. $M$. japonica is strikingly and rather consistently marked (1) by the long corolla tubes which are two or three times the length of the lobes, (2) by the wide subfloral bracteols which clasp the base of the hypanthium, and (3) by rather coriaceous sub-entire or remotely serrate leaves. The specimen here considered, however, has some corolla tubes equaling and some twice as long as the corolla lobes, ovate but not clasping bracteoles, and rather thinner and oblanceolate leaves. The inflorescences, moreover, have more tendency to branch than is common in Maesa japonica. The flowers are smaller than those typical of M. japonica. However, in the erratically elongated corolla tubes it seems to resemble that species rather than $M$. tenera, to which it seems also related. No specimens I have seen of this latter species, however, have any flowers with such long corolla tubes. Furthermore, the leaves of $M$. tenera are much more coarsely serrate and are elliptic rather than oblanceolate, the latter a shape which may be found among M.japonica specimens. Thus Bentham's variety seems to straddle the boundary that is usually rather clearly marked between $M$. japonica and $M$. tenera. The evidence suggests that it is possibly of hybrid origin, a theory which should be held in abeyance until evidence can be obtained by controlled hybridizing of these species.

The transfer by Nakai of var. gracilis Benth. from $M$. coriacea to $M$. japonica seems acceptable since $M$. coriacea Champ. is properly a synonym of $M$. japonica (Thunb.) Moritzi. The taxa M. japonica var. elongata Mez, M. esquirolii Lév'l., $M$. randaiensis Hayata, and $M$. taiheizanensis Sasaki are all placed by Nakai as synonyms of $M$. japonica f. gracilis (Benth.) Nakai. The types or isotypes which $I$ have seen of these reduced taxa, however, differ from the Wilford specimen from Hongkong of f. gracilis, which apparently Nakai did not see, and which it has already been pointed out is significantly different from $M$. japonica. In my revision $M$. japonica var. elongata $\mathrm{Mez}$ was reduced to a synonym of $M$. japonica (29, pp. 19 and 22). Nakai (18, p. 10) seems to consider my interpretation, assuming his citation of Henry 7957 is an error for 7757 , in recognizing this as a synonym, but links it with $\mathrm{f}$. gracilis. M. esquirolii Lév'l. was placed by me $(29$, p. 19) as a synonym of $M$. japonica (Thunb.) Moritzi. Since I discussed M. randaiensis Hayata as an uncertain species I have examined (1951) the type in the herbarium of the University of Tokyo and find that, although it has narrower leaves, it is too inadequate a specimen to be referred to any separate variety or form. The type Maesa taiheizanensis Sasaki has not been seen. After examining the assemblage of specimens in the Tokyo herbarium which have been referred to f. gracilis by Nakai, I am convinced they 
represent variations which are probably to be found in any large assemblage of specimens of $M$. japonica. It seems to me, therefore, that, if there is in Japan a taxonomically recognizable narrow-leaved variant of $M$. japonica, it has not yet been clearly differentiated and properly named. Since var. elongata is untenable this variant can not be " $f$. elongata $(\mathrm{Mez})$ Makino in Zissai Engei XXVI, 1082 in textu (1940)" noted by Hara (5, p. 80).

(b) Maesa japonica f. latifolia (Miq.) Nakai (Nakai p. 10): The status of this form is the same as is that of the preceding form. The type is obviously that which was cited by $\mathrm{Mez}$ as "Siebold (Herb. Leiden)". Nakai seems to have examined this specimen $(17$, p. 10$)$ but I have not been able to do so. I have examined in the Tokyo herbarium the two specimens discussed by Nakai and find them rather strikingly different in leaf width and size from the other specimens available, but they also differ from each other. Nakajima's specimen is sterile. Matsumura's came from a cultivated plant. Probably they represent either the vigor of a new shoot or a horticulturally developed form. Further study of abundant cultivated and wild plants is needed to resolve the validity of this form.

(c) Maesa augustini (Nakai) Tuyama (Nakai, p. 14): I have examined the type and other specimens in the Tokyo herbarium which were studied by Nakai and have studied his key, p. 11, and his description, p. 14, both in translation. The references to minute pubescence on the branches seems only partly substantiated. A few specimens of $M$. tenera $\mathrm{Mez}$ from Formosa and the Ryûkyû Islands have a slight tendency to be pubescent. I cannot give taxonomic significance to the color characters described by Nakai. Comparison of leaf margins in the type specimen of $M$. augustini, which was taken from a cultivated plant in the Kiyose Experimental Station on Chichi-jima in the Bonin Islands with specimens collected by Tuyama on cliffs of Minami Iwo Jima (or South Sulphur Island, originally called St. Augustine Island), whence the type plant originally came, shows differences in teeth shape, size, and number more prominent than these differences in pubescence. Thus, I am compelled to consider $M$. augustini (Nakai) Tuyama as a synonym of M. tenera Mez. In my early attempts to understand $M$. perlarius (Lour.) Merr. and M. tenera $\mathrm{Mez}$ I was compelled to recognize much variability and intergrading. In fact, separation of nearly all of the species of Maesa was more difficult and less satisfactory than in any other genus of Myrsinaceae which I have yet studied.

\section{Calispermum}

(a) Calispermum oblongifolium (Hemsl.) Nakai (Nakai, p. 18): Embelia lenticellata Hayata was placed by Nakai as a synonyrn of $C$. oblongifolium, but in my revision, p. 168, it is a valid species. Although I had not seen the type, I considered from an examination of the literature that E. H. Wilson 10,865 from Formosa represented Embelia lenticellata. I have now, however, seen Hayata's type, Kawakami \& Mori 3465 and their number 1841, both in the herbarium of the University of 
Tokyo. They confirm my earlier acceptance of the Wilson specimen as representing a species distinct from Embelia oblongifolia Hemsl. Nakai gives no indication of what specimens he had from China of Calispermum oblongifolium (Hems1.) Nakai (Embelia oblongifolia Hems1.) and I found in his studied material in Tokyo only one specimen from there. He laid stress in his discussion on the similarity of sepals and the unreliability of differences in veins because of varying techniques in drying specimens. He might have added the variability of leaf shape in Embelia oblongifolia, if more abundant material had been available. Nevertheless, the venation and leaf of $E$. lenticellata Hayata give definite evidence of its distinctness, a conclusion I came to even before seeing Hayata's type. The available material, including a fragment of Hayata's type, has been examined by Dr. Hui-Lin $\mathrm{Li}$, who confirms my conclusion.

(b) Calispermum rude (Hand.-Mazz.) Nakai, Bot. Mag. Tokyo 55: 527. 1941 (Nakai, p. 20): Nakai's original transfer of this name gave no indication of its origin, i.e., the basonym or name bringing synonym. The name merely appeared in a list. For that date (1941) such a transfer was not in violation of the rules. Beginning with January 1, 1953, however, according to Section 6, Article 42, paragraph 2 of the International Code (8), such a transfer would be invalid. The basonym must be stated. The specimen in the University of Tokyo herbarium from Formosa, which was labeled by Hara and mentioned by Nakai at the end of his discussion, has been examined.

\section{Samara}

Samara laeta var. papilligera Nakai (p. 24): Nakai bases this new variety on Embelia penduliramula Hayata. Nakai's material in the University of Tokyo herbarium, consisting of three specimens besides the type, has been examined. His revision of my tabular comparison $(29$, p. 183) of the original description of Embelia penduliramula Hayata with my concept of Embelia laeta (L.) $\mathrm{Mez}$ seems itself to need slight revision. I find that my interpretation of Hayata's description "pedicels glandular puberulent" is more applicable than Nakai's "pedicels minutely puberulent". Pedicel length here certainly has no taxonomic significance. However, the constant character separating E. penduliramula and E. laeta is the minutely papillose character of the branchlets and branches of the inflorescence in the former. Reexamination of available specimens of E. laeta (L.) $\mathrm{Mez}$ (Samara laeta L. of Nakai's treatment) reveals three specimens from China which have this characteristic, which was not recognized when I prepared my revision. Thus the range of this variety may be extended. Since I do not agree with the reestablishing of Samara, this should be:

Embelia laeta var. papilligera (Nakai) Walker, comb. nov., based on the type of Embelia penduliramula Hayata, collected by B. Hayata from "Mt. Arisan, inter Heishana et Nimandaira, ad 7000 ped. alt., Aprili (fl. et fr.) 1914", in the Herbarium of the University of Tokyo (fragment in the U.S. National Herbarium). Additional specimens: China, Kwangtung Province, Ho-yuen District 河源縣：W.T. Tsang 
28512, Mar. 16-31, 1938 from Kwai Shan 桂山, and 28762, May 5-30, 1938, from 梢山; Kiangsi Province, Kiennan District 虔南縣： S. K. Lau 3983, July 28-30, 1934 from Sai Hang Cheung 西坑障, all in the U.S. National Herbarium.

\section{Ardisia-Bladhia}

\section{Ardisia Swartz or Bladhia Hornst.5) (Nakai, p. 28):}

Nakai uses the name Bladhia whereas Ardisia appears in my revision. Nakai in 1921 (14) transferred to Bladhia all the Japanese species of Ardisia which had not previously been ascribed to that genus. The following of this procedure by most, but not all, Japanese botanists since that time has complicated the nomenclature of eastern Asiatic Myrsinaceae. The latest exception is found in 1953 in Jisaburô Ohwi, Flora of Japan (19), Ardisia being used there instead Bladhia. No clear explanation of the basis of this use of Bladhia has been available in English. Explanations are given in Japanese in Nakai's 1921 paper (14), in his phylogeny of the Ardisiaceae (17), and in his revision (18). Following is a translation prepared by Luhrs Stroud, revised by H.L. Li, of Nakai's discussion in the latter work, under Tribe Ardisieae, p. 26-27, where there is an excellent drawing of the type species, A.tinifolia Swartz:

"Shrubs or trees or procumbent small shrubs [i.e., suffrutescent undershrubs]; glabrous or hirsute or scaly [i.e., lepidote]. Leaves persisting 2 years, alternate, opposite, or whorled. Inflorescence corymbose or compound corymbose, or a terminal panicle. Flowers 5- or 4-merous; the sepals separate, sepals and petals dextrorsely imbricate; the ovules in 1-3 rows on the placenta; the albumen bony and smooth."

"Genera 6 with one Japan."

"The International Committee on the Rules of Botanical Nomenclature rejected Bladhia and accepted Ardisia Swartz as a nomen conservandum. According io the International Rules of Botanical Nomenclature, this decision must be followed if it is accepted at the next general meeting of the Congress, and cannot be reversed. But in adopting Bladhia, [I use] it in a special meaning distinct from Ardisia. There are over 10 species of Ardisia (type species A. tinifolia Swartz), primarily in South America, but with some species in South China, Indo-China, and eastern India [? East Indies]. The inflorescence is a terminal compound raceme and not a lateral corymb or cyme, which characterizes Eubladhia, Crispardisia, and Tinus. The anthers open at the apex by pores. It is separated from the section and species of Eubladhia by the united or distinct petals, the number of ovules in the placenta, the number of parts in

5) Bladhia is usually attributed to Thunberg. It actually appeared in the Thunbergian dis. sertation "Nova genera plantarum, quorum partem primam" by C.F. Hornstedt, 28 pp., 1781, republished as "Dissertatio de novis generibus plantarum", in C.P. Thunberg, "Dissertationes academicae Upsaliae habitae sub praesidio Caroli Petri Thunberg", 1: 1-28. 1799. Thunberg himself attributed Bladhia japonica to Hornstedt (cf. Thunb. Fl. Jap. 95. 1784). 
the flower, the shape of the inflorescence, the presence or absence of bracteoles or bractlets on the pedicels, the shape of the stigmas, the arrangement of the corolla lobes, and the nature of the albumen. These are important phylogenetic differences distinguishing tribes and genera. Disregard or overlooking of these points by American and European scientists reveals their classification as artificial and imperfect."

Ardisia was founded in 1788 on a West Indian species A. tinifolia Swartz, and Bladhia in 1781 on a Japanese species, B. japonica Hornsted. Ardisia is a conserved generic name (8, p. 144). Mez recognized the distinctness of Bladhia by linking with the type species 8 other species ranging from Java and Sumatra to Japan. Its similarity to Ardisia was recognized by him in establishing it as a subgenus of Swartz' genus Ardisia. Pitard (20) in 1930 placed Mez' Indo-China species in "Crispardisia Mez". In my revision (29) 12 species of "Sect. Bladhia (Thunb.) $\mathrm{Mez}$ "6) were recognized, some new and some described by others since Mez' monograph was published in 1902. However, I rejected two species included by $\mathrm{Mez}$ in order to include in Section Crispardisia all the species which have leaves with resinous marginal glands. Mez' description stresses fewer ovules, the herbaceous or suffrutescent and low creeping habit, the more serrate leaves, and the axillary umbellate or corymbose or small paniculate inflorescences. I added the lack of albuminous or resinous marginal glands.

Nakai thus separates Ardisia from Bladhia on the terminal inflorescence and the apical pores of the dehiscing anthers. He suggests other characters in the division of the corolla, the imbrication of the petals, the number of ovules, the number of parts in each floral whorl, the bracts in the inflorescence, the stigmas, and the form of the albumen, but these differences have nowhere been critically and thoroughly elaborated by him with cited specimens to document his conclusions. His Japanese description of Bladhia on p. 29 of his treatment is simply a generic description covering the species he includes. It contains nothing more that clearly differentiates them from his accepted Ardisia species.

I do not find that the differentiating characters given by Nakai are incompatible within one genus, in view of the numerous characters which link together the several hundred species generally accepted in this genus. Nakai's characters, therefore, do not seem to me to be of significant phylogenetic importance. If theyare of such importance, this fact has not yet been amply demonstrated. Again it seems evident that one cannot make valid analysis of the subdivisions of a taxonomic unit, whether a genus or a group of genera, by studying only a geographically limited number of species (see discussion p. 109). Thus I do not believe Bladhia as a genus can be differentiated from Ardisia. Bladhia makes a convenient subdivision, preferably

6) It is again unfortunate that this was not called a subgenus as designated by Mez (see also p. 111 footnote 4). Also the parenthetical authority should have been Hornsted, (see discussion p. 159 , footnote 5 ). 
a subgenus, of Ardisia, if defined as $\mathrm{Mez}$ and I have done. Its enlargement as a subgenus by the addition of other species than those recognized by $\mathrm{Mez}$, as by the transfer to it of some of Pitard's species, only emphasizes its perhaps artificial segregation within the genus Ardisia. The species are best held together by a common habit of growth. The two species which I rejected from Mez' concept of Subgenus Bladhia, namely A. mamillata Hance and A. primulifolia Gard. \& Champ., are similar in habit. Could the species which I include in Subgenus Bladhia represent the suffrutescent members of the Subgenus Akosmos, as defined by Mez, which lacks marginal glands, and my species, removed from Mez' concpt of Subgenus Bladhia, represent the same tendency in Subgenus Crispardisia, which does have marginal glands? I do not believe there is sufficient evidence to establish such a theory and that our groupings do and probably always will contain much that is only artificial and convenient.

\section{Subdivisions of Blahdia or Ardisia :}

Nakai recognizes four sections for the genus Bladhia Thunb., namely the Section Eubladhia Nakai, Chinensis Nakai, Crispardisia (Mez) Nakai, and Tinus (Mez) Nakai, $\mathrm{Mez}$ designated his subgeneric units as subgenera (although under the genus Ardisia instead of Bladhia, a difference to be discussed later). Changing these units from subgenera, as $\mathrm{Mez}$ designated his first subgeneric unit, to sections requires designation by double authorities (cf. Art. 59 of the 1952 Code (8)). Since the first two are entirely new and the others are transfers, these aurhorities appear to be correct. However, in my treatment (29) the subdivisions of Ardisia are designated as sections, and Crispardisia and Tinus are both attributed to $\mathrm{Mez}$ and are used in the same sense as $\mathrm{Mez}$ used them. I regret having made this inadvertent and purposeless change from subgenera to sections. However, since they are made and since Nakai designates them as Sections, they should be Section Crispardisia (Mez) Walker and Section Tinus (Mez) Walker, even though he places them under Bladhia instead of Ardisia. The reasons presented in discussing Maesoideae on p. 109 preclude the use here of "Nakai" as authority because of their use under Bladhia instead of Ardisia as in my treatment.

The separation of Sect. Eubladhia Nakai, with serrate opposite leaves and stems procumbent above ground or among fallen leaves, from Sect. Chinensis with entire alternate leaves and stems crawling below ground (see key in Nakai's Ardisiaceae, p. 29) is one of the most clear cut distinctions recognized by Nakai. If it should seem beneficial to establish sections in my treatment, after reestablishing Bladhia properly as a subgenus instead of a section, as I inadvertently made it, then his sections could well be recognized.

Nakai in 1941 (17, p. 524) established Section Crispardisia (Mez) Nakai based on Subgenus Crispardisia Mez. Section Crispardisia Mez rather than Subgenus Crispardisia Mez inadvertently appeared in 1940 in my revision (29, p. 82), a publication 
perhaps not known to Nakai when he issued his phylogentic treatment of the Ardisiaceae in 1941 . This section is well characterized and readily recognized by the albuminous or resinous marginal glands on the leaves variously related to the serration, crenation or undulation of the margin. According to Jongh (7) these albumin secreting glands result from the activity of Bacillus follicola associated with hydathodes in the leaves. Thus the Subgenus or Section Crispardisia seems to owe its identity to the physiological activity of a symbiont. Is this a phylogenetic or an artificial characterization of a taxonomic unit? One wonders about the phylogeny of other species, presumably having hydathodes, but which do not respond to and therefore perhaps inhibit or eliminate corresponding bacterial action. Doubtless phylogeny is legitimately traceable through physiological as well as morphological characteristics.

Section Tinus (Mez) Nakai should technically but unfortunately be Sect. Tinus (Mez) Walker. Nakai explains $(18$, p. 117) that this section contains more than 60 species including those with strongly imbricated and those with not strongly imbricated sepals. He thus combines the subgenera Tinus and Akosmos, which were recognized as distinct by $\mathrm{Mez}$, Pitard, and Walker. He ignores the subgenus Acrardisia Mez, doubtless because it contains no Japanese species. Subgenus Tinus (Burm.) Mez is represented in this area by "Bladhia racemosa (Lour.) Nakai," which occurs in Botel Tobago (Kôtôshô) off the southeastern coast of Formosa. The confusion in the nomenclature of this species will be discussed later. Subgenus Akosmos $\mathrm{Mez}$ contains 3 Japanese and 4 Formosan species according to $\mathrm{Mez}$ (12) and 2 according to my treatment (29). It is difflcult to understand how one who has compared the broad and usually conspicuously overlapping sepals of Ardisia arborescens Wall., $A$. solanacea Roxb., and $A$. humilis Vahl of the section Tinus (Burm.) Mez (as interpreted by Walker, not by $\mathrm{Mez}$ or Nakai) with those of $A$. sieboldii Miquel and $A$. quinquegona Blume of Section Akosmos $\mathrm{Mez}$ can state that it is impossible to define boundaries in this assemblage, and that therefore they should be grouped in a natural division or assemblage as Sect. Tinus (Burm.) Mez. There are indeed borderline examples, but these are few. These subgenera are certainly as readily separable as are the two sections, of Maesa which are recognized by Nakai (see p. 155). 